\title{
Structural and Functional Causes of Hypernasality in Velocardiofacial Syndrome
}

\author{
A Pilot Study
}

\author{
Adriane L. Baylis ${ }^{a}$ Peter J. Watson ${ }^{b}$ Karlind T. Moller ${ }^{b}$ \\ ${ }^{a}$ Children's Hospital of Wisconsin and Medical College of Wisconsin, Milwaukee, Wisc., b University of Minnesota, \\ Minneapolis, Minn., USA
}

\section{Key Words}

Velocardiofacial syndrome $\cdot 22 q 11$ deletion

\begin{abstract}
Objective: Hypernasality in velocardiofacial syndrome (VCFS) is more severe, persistent, and difficult to manage compared to other populations with cleft palate or velopharyngeal (VP) dysfunction. This pilot study investigated why children with VCFS have more severe hypernasality. Methods: Pressure-flow methodology indirectly measured VP orifice size and VP closure timing during speech in a group of 5 children with VCFS, 5 children with cleft palate, and 6 normal children. Results: Children with VCFS demonstrated significant differences in VP closure timing and hypernasality. There were no significant group differences in VP orifice size. Duration of nasal airflow was the strongest predictor of judgments of hypernasality. Conclusion: This study provides preliminary evidence that VP closure timing may account for the more severe hypernasality in children with VCFS, compared to structural factors alone.
\end{abstract}

Copyright $\odot 2009$ S. Karger AG, Basel
(C) 2009 S. Karger AG, Basel

1021-7762/09/0612-0093\$26.00/0

Accessible online at:

www.karger.com/fpl

\section{Background}

Velocardiofacial syndrome (VCFS) is a genetic disorder involving velopharyngeal (VP) dysfunction, cardiac defects, and developmental problems [1], and is caused by a chromosomal 22q11.2 deletion, occurring in 1/4,000 births [2,3]. Hypernasal speech is a hallmark of VCFS [1], resulting from a variety of anomalies including cleft palate, submucous cleft palate, palatopharyngeal hypotonia, deep retropharynx, or anterior positioning of the levator palatini $[1,4,5]$. While hypernasality is often eliminated in patients with nonsyndromic cleft palate with traditional surgical approaches, speech outcomes in the VCFS population have been less than optimal [6-8]. Losken et al. [8] found that children with VCFS with a larger VP orifice $\left(>30 \mathrm{~mm}^{2}\right)$ were more likely to require additional surgery to reduce hypernasality. VP orifice size has repeatedly been shown to be related to perceptions of increased nasality in the cleft population [9-12]. The relation between VP orifice size and hypernasality in VCFS remains largely unexplored.

For some individuals with cleft palate, VP orifice size does not highly correlate with perceptions of hypernasality; a higher correlation has been found in relation to the timing of VP closure during speech [10, 11, 13]. Riski [14] showed that some children with VCFS with a small VP 


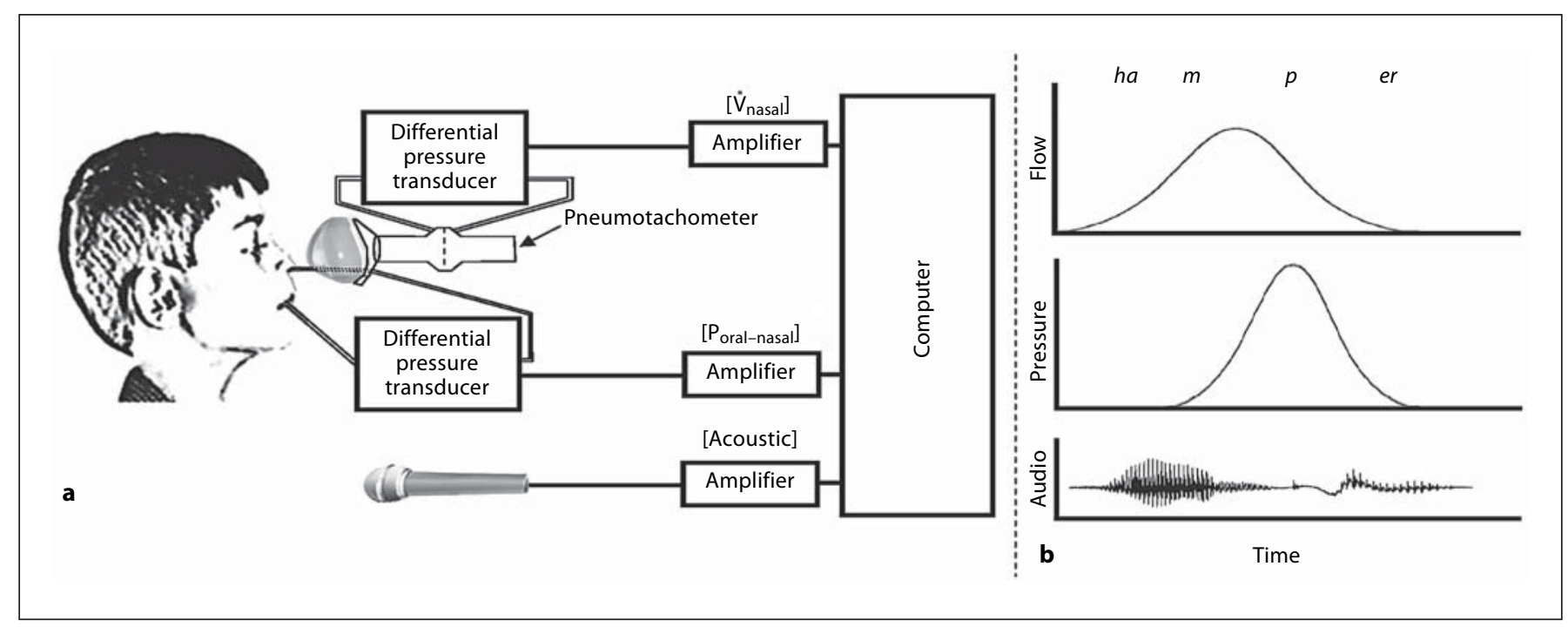

Fig. 1. a Schematic of pressure-flow instrumentation. b Stereotypical pressure, flow, and acoustic waveforms during the production of the word hamper.

orifice have higher nasalance scores. These findings support the hypothesis that temporal variables related to VP closure play a role in the perception of hypernasality in VCFS. Few studies have explored VP orifice size in VCFS, and to date there are no studies examining VP closure timing in this syndrome. The specific questions of this study included: (1) Do children with VCFS have a larger VP orifice area than children with nonsyndromic cleft palate? (2) Do children with VCFS exhibit differences in the timing of VP closure? (3) Are VP timing measurements a better predictor of perceptual speech judgments of nasality than VP orifice size?

\section{Method}

\section{Participants}

This study was IRB-approved. Three groups of children participated: (1) a VCFS group ( $\mathrm{n}=5 ; 1$ male, 4 females, mean age 7.7 years), with a confirmed 22q11.2 deletion; (2) a cleft palate (CLP) group ( $\mathrm{n}=5 ; 3$ males, 2 females, mean age 10.4 years), with nonsyndromic cleft lip and palate; (3) a normal speech and language (NSL) control group ( $n=6 ; 3$ males, 3 females, mean age 5.9 years), with no history of cleft palate or VP dysfunction. Differences in ages between groups were nonsignificant $(p>0.39)$. One participant in the CLP group and 3 participants in the VCFS group had a pharyngeal flap. Participants with a history of cleft palate had undergone palate repair (one-stage) and had no oronasal fistulae (confirmed by medical records and oral examination). All participants demonstrated normal articulation skills during a conversational speech sample and sentence repetition task during a clinical-speech evaluation. All participants spoke English as their primary language and passed a pure-tone hearing screening at 20 dB HL. A standard speech sample was recorded for each speaker and later used to make perceptual speech judgments. Participants were asked to read aloud a phonetically balanced paragraph ('Lazy Jack Passage') and repeat oral-only sentences (e.g., This is the house that Jack built.) and oral-nasal mixed sentences (e.g., I took a sample of the peanut butter.).

\section{The Pressure-Flow Method}

Pressure-flow testing, similar to the method of Warren et al. [13], was conducted to obtain indirect structural and functional measurements of VP orifice size and VP closure timing during speech. All equipment was calibrated immediately before each participant. Nasal resistance was informally screened prior to data collection. Pressure-flow measurements were obtained using two differential pressure transducers. Differential pressure $(\Delta \mathrm{P})$ across the VP orifice was measured using the setup depicted in figure 1. Nasal airflow $\left(\mathrm{V}_{\mathrm{N}}\right)$ was measured using a pneumotachograph attached to a pediatric-sized nasal mask. A microphone was positioned near a participant's mouth to record the acoustic signal during pressure-flow data collection. Participants repeated the phrase A hamper again 5 times, with stress on the first syllable of hamper and a breath between each phrase. The word hamper was used because it evaluates the dynamic and static aspects of VP function [13].

The hydrokinetic equation [13] was used to calculate VP ori-

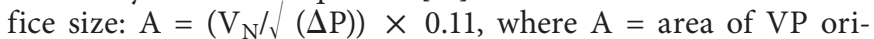
fice $\left(\mathrm{cm}^{2}\right), \mathrm{V}_{\mathrm{N}}=$ nasal airflow $(\mathrm{ml} / \mathrm{s}), \Delta \mathrm{P}=$ differential pressure (oral - nasal pressure), and 0.11 is a constant that accounts for the flow coefficient $(\mathrm{k})$, the density of air, and a conversion factor [15]. VP closure timing was calculated from the duration of the nasalairflow pulse during the production of the $/ \mathrm{m} /$ to the $/ \mathrm{p} /$ sound (in hamper), and VP orifice size was estimated at the pressure peak of $/ \mathrm{p} /$. There were no group differences in average speech rate (VCFS 4.54, CLP 4.69, NSL 4.59 syllables/s, p > 0.46). 
Data Analysis

Five adult listeners, graduate students who had completed a semester-long practicum at a cleft palate clinic, made perceptual judgments of nasality based on the recorded speech samples. Listeners used direct magnitude estimation with a modulus to judge. Listeners were blinded to the age and diagnosis of the speaker. Samples were presented in randomized order at approximately 65 dB HL for each listener, while seated approximately 4 feet away from two loudspeakers. Two samples were replayed a second time to each listener to obtain a measure of intrarater reliability $(\mathrm{r}=$ 0.98). Judgments of nasality were averaged by calculating the geometric mean of all listeners' ratings for each speech sample and each speaker [16].

Independent variables included: (1) group, (2) VP orifice size, and (3) nasal airflow pulse duration. The dependent variable was the averaged perceptual ratings of severity of nasality. Nonparametric statistics were used based on the small sample size and lack of a normal distribution. Kruskal-Wallis and Mann-Whitney U tests were used to determine if group differences existed $(\alpha=$ $0.05)$. Regression analysis was used to explore predictors of judgments of nasality.

\section{Results}

Group differences in ratings of nasality were found to be significant, with the VCFS group having the most severe nasality, followed by the CLP group $\left(\chi^{2}=7.64\right.$, d.f. $=$ $2, \mathrm{p}<0.022)$. Nasality ratings for the VCFS group were significantly different from the NSL group $(\mathrm{p}<0.016)$ and approached a significant difference from the CLP group $(\mathrm{p}<0.061)$. Listener ratings of nasality were almost twice as severe for the VCFS group (see figure 2 for a distribution of ratings). There were no significant group differences in VP orifice size (VCFS: mean $1.187 \mathrm{~cm}^{2}$, SD 1.660; CLP: mean $0.294 \mathrm{~cm}^{2}$, SD 0.262; NSL: mean 0.012 $\mathrm{cm}^{2}$, SD 0.013; $\chi^{2}=5.29$, d.f. $\left.=2, \mathrm{p}>0.07\right)$. The VCFS group had the largest mean VP orifice area compared to the other two groups, but also had the largest variability.

Significant group differences were found for VP closure timing (VCFS: mean 0.176, SD 0.042; CLP: mean 0.143 , SD 0.065; NSL: mean 0.100, SD 0.028; $\chi^{2}=5.981$, d.f. $=2, \mathrm{p}<0.05)$. The duration of the nasal airflow pulse was significantly longer for the VCFS group compared to the NSL group $(\mathrm{p}<0.009)$. Stepwise linear regression analysis revealed that the duration of nasal airflow was a significant predictor of judgments of nasality for all three groups of participants $\left(\mathrm{F}=6.32\right.$, d.f. $=15, \mathrm{p}<0.03, \mathrm{r}^{2}=$ 0.31 ; fig. 2). When VP orifice size was added as a predictor, regression results were no longer significant $(\mathrm{F}=3.74$, d.f. $=15, \mathrm{p}>0.05)$. Not all the children with VCFS had a larger VP orifice compared to children in the CLP group,

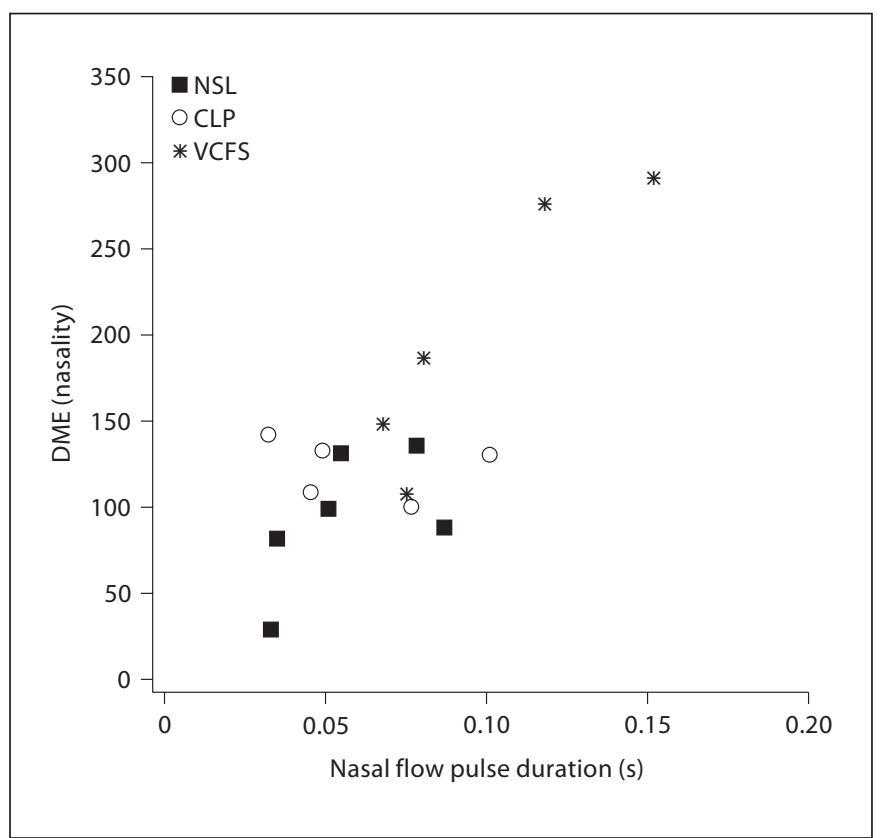

Fig. 2. Scatterplot showing the relation between nasal-flow pulse duration and the judgment of nasality, using direct-magnitude estimation (DME), for all three groups.

even though almost all the children with VCFS had higher ratings of nasality. For example, several subjects in the VCFS group had relatively smaller VP orifice sizes, but were all judged to have more severe nasality than children in the CLP and control group.

\section{Discussion}

The main limitations of this study include the small sample size and the heterogeneity of the participants with VCFS, which limits our ability to draw conclusions and generalize these findings to the broader VCFS population. Two of the 4 participants with a pharyngeal flap did not have a large VP orifice area or the longest durations of nasal airflow compared to the 2 other participants with a flap. These latter 2 participants had larger VP openings and longer durations of nasal airflow, and it cannot be determined from this study if this relation is correlational or causal. This study provides new information regarding potential differences in VP closure timing in children with VCFS. Duration of the nasal airflow, which reflects the duration that the VP port was open, was found to be a better predictor of listener judgments of nasality compared to VP orifice size alone. Hypernasality in the pres- 
ence of a small VP orifice area, and better associated VP closure timing differences, suggests the possibility of deficits in speech-motor control in children with VCFS. This is not surprising given evidence of broader neuromotor differences in VCFS including smaller diameter and reduced thickness of the superior pharyngeal constrictor muscle, brain abnormalities (e.g., cerebellum, thalamus), generalized hypotonia and motor delays [17-20]. Future research should continue to investigate VP structural and timing differences in a larger sample of children with VCFS to determine if this is seen in the broader popula- tion or is a reflection of a subgroup within the syndrome. The speech performance of children with VCFS should also be compared to other children with known neuromuscular speech disorders.

\section{Acknowledgment}

Funding for this study was provided by the Ralph B. Kersten Research Fund of the University of Minnesota Cleft Palate Clinic.

\section{References}

1 Shprintzen RJ, Goldberg RB, Lewin ML, et al: A new syndrome involving cleft palate, cardiac anomalies, typical facies, and learning disabilities: velocardiofacial syndrome. Cleft Palate J 1978;15:56-62.

2 Devriendt K, Fryns JP, Mortier G: The annual incidence of DiGeorge/velocardiofacial syndrome. J Med Genet 1998;35:789-790.

3 Scambler PJ, Kelly D, Lindsay E, et al: The velocardiofacial syndrome is associated with chromosome 22 deletions encompassing the DiGeorge locus. Lancet 1992;333:11381139.

4 Arvystas M, Shprintzen RJ: Craniofacial morphology in the velocardiofacial syndrome. J Craniofac Genet Dev Biol 1984;4: 39-45.

5 Kuehn DP: MRI investigation of VCFS. American Cleft Palate Craniofacial Association Annual Meeting, Greenville, 2003.

6 D’Antonio LL, Davio M, Zoller K, et al: Results of Furlow Z-plasty in patients with VCFS. Plast Reconstr Surg 2001;107:10771079.

7 Milczuk HA, Smith DS, Brockman JH: Surgical outcomes for VP insufficiency in VCFS and non-syndromic patients. Cleft Palate Craniofac J 2007;44:412-417. $\checkmark 8$ Losken A, Williams JK, Burstein FD, et al: Surgical correction of VP insufficiency in children with VCFS. Plast Reconstr Surg 2006;117:1493-1498.

-9 Warren DW, Dalston RM, Morr KE, et al: The speech regulating system: temporal and aerodynamic responses to velopharyngeal inadequacy. J Speech Hear Res 1989;32:566575.

10 Warren DW, Dalston RM, Mayo R: Hypernasality and velopharyngeal inadequacy. Cleft Palate J 1994;31:257-262.

11 Warren DW, Dalston RM, Mayo R: Hypernasality in the presence of 'adequate' velopharyngeal closure. Cleft Palate Craniofac J 1993;30:150-154.

12 Kummer AW, Briggs M, Lee L: The relationship between characteristics of speech and velopharyngeal gap size. Cleft Palate Craniofac J 2003;40:590-596.

13 Warren DW, Dalston RM, Trier WC, et al: A pressure-flow technique for quantifying temporal patterns of palatopharyngeal closure. Cleft Palate J 1985;22:11-19.

14 Riski J: Velopharyngeal dysfunction in VCFS. 10th Annual International Meeting of the Velocardiofacial Educational Foundation and 4th International Congress for 22q11.2 deletion, Atlanta, 2004.
15 Zajac DJ, Yates CC: Accuracy of the pressure flow method in estimating induced velopharyngeal orifice area: effects of the flow coefficient. J Speech Hear Res 1991;34:10731078 .

16 Stevens SS: Psychophysics: Introduction to Its Perceptual, Neural, and Social Prospects. New York, Wiley, 1975.

17 Zim S, Schelper R, Kellman R, et al: Thickness and histologic and histochemical properties of the superior pharyngeal constrictor muscle in velocardiofacial syndrome. Arch Facial Plast Surg 2003;5:503-510.

18 Hultman CS, Riski JE, Cohen SR, et al: Chiari malformation, cervical spine anomalies, and neurologic deficits in velocardiofacial syndrome. Plast Reconstr Surg 2000;106:1624.

19 Simon TJ, Ding L, Bish JP, et al: Volumetric, connective, and morphologic changes in the brains of children with chromosome 22q11.2 deletion syndrome: an integrative study. Neuroimage 2005;25:169-180.

20 VanAken K, DeSmedt B, Van Roie A: Motor development in school-age children with 22q11 deletion. Dev Med Child Neurol 2007; 49:210-213. 